\title{
Commentary: A Reassessment of the Taxonomic Position of Mesosaurs, and a Surprising Phylogeny of Early Amniotes
}

\author{
Mark J. MacDougall ${ }^{1 *}$, Sean P. Modesto ${ }^{2}$, Neil Brocklehurst ${ }^{1}$, Antoine Verrière ${ }^{1}$, \\ Robert R. Reisz ${ }^{3}$ and Jörg Fröbisch ${ }^{1,4}$ \\ ${ }^{1}$ Museum für Naturkunde, Leibniz-Institut für Evolutions- und Biodiversitätsforschung, Berlin, Germany, ${ }^{2}$ Department of \\ Biology, Cape Breton University, Sydney, NS, Canada, ${ }^{3}$ Department of Biology, University of Toronto Mississauga, \\ Mississauga, ON, Canada, ${ }^{4}$ Institut für Biologie, Humboldt-Universität zu Berlin, Berlin, Germany
}

Keywords: Mesosauridae, Parareptilia, Sauropsida, Palaeozoic, Reptilia, phylogenetics

\section{OPEN ACCESS}

Edited by:

Torsten M. Scheyer,

Universität Zürich, Switzerland

Reviewed by:

Richard J. Butler,

University of Birmingham,

United Kingdom

Juliana Sterli,

Consejo Nacional de Investigaciones Científicas y Técnicas (CONICET),

Argentina

Stuart Sumida,

California State University, San

Bernardino, United States

${ }^{*}$ Correspondence:

Mark J. MacDougall

mark.macdougall@mfn.berlin

Specialty section

This article was submitted to

Paleontology,

a section of the journal

Frontiers in Earth Science

Received: 15 March 2018

Accepted: 29 June 2018

Published: 25 July 2018

Citation:

MacDougall MJ, Modesto SP,

Brocklehurst N, Verrière A, Reisz RR and Fröbisch J (2018) Commentary: A

Reassessment of the Taxonomic

Position of Mesosaurs, and a

Surprising Phylogeny of Early

Amniotes. Front. Earth Sci. 6:99.

doi: 10.3389/feart.2018.00099

\section{A Commentary on}

A Reassessment of the Taxonomic Position of Mesosaurs, and a Surprising Phylogeny of Early Amniotes

by Laurin, M., and Piñeiro, G. H. (2017). Front. Earth Sci. 5:88. doi: 10.3389/feart.2017.00088

\section{INTRODUCTION}

The enigmatic amniote clade Mesosauridae has long been of interest to those that study Palaeozoic tetrapods, largely due to the fact that the group contains the oldest secondarily aquatic tetrapods. They are also further notable due to being the oldest amniotes known from southern palaeolatitudes (Modesto, 2010), and for being an important line of evidence for Alfred Wegener's theory of continental drift (Wegener, 1915), which later led to today's theory of plate tectonics.

The exact position of the clade Mesosauridae within Amniota has always been slightly problematic. Prior to the development of phylogenetic systematics, mesosaurs were assigned to numerous different tetrapod groups. Gervais (1865) considered mesosaurs to be closely related to Sphenodon, whereas Cope (1886) assigned them to "?Batrachia," Baur (1889) hypothesized that they may be ancestral to amniotes, and von Huene (1941) suggested that they were closely related to basal pelycosaurs. With the advent of phylogenetic systematics, numerous studies incorporated mesosaur taxa into their analyses, the first being the pioneering study by Gauthier et al. (1988), which recovered mesosaurs as the sister to all other parareptiles. Later studies recovered mesosaurs in varying places within Amniota, with one study recovering mesosaurs as the basal-most lineage of a clade to which the name Sauropsida was attached (Laurin and Reisz, 1995). Numerous others recover it as the sister to all other parareptile clades (Tsuji et al., 2012; Modesto et al., 2015; MacDougall et al., 2016, 2017) replicating the results of Gauthier et al. (1988), and one study recovers the clade being nested within Parareptilia as the sister taxon of bolosaurids (Bever et al., 2015). The 2017 paper "A Reassessment of the Taxonomic Position of Mesosaurs, and A Surprising Phylogeny of Early Amniotes" by Laurin and Piñeiro is the latest publication to tackle the issue of the phylogenetic position of Mesosauridae. The results of their phylogenetic analysis reaffirm the Laurin and Reisz (1995) placement of Mesosauridae at the very base of Sauropsida (sensu Laurin and Reisz, 1995, in which Sauropsida = Mesosauridae + Reptilia). Furthermore, their phylogenetic analysis also produced the unique tree topology of having the remaining Parareptilia nested within Eureptilia as the sister taxon of younginiforms. 
While the results of Laurin and Piñeiro (2017) are interesting, there are issues with the methodology and interpretations of the study that render them problematic. Firstly, it is perplexing that the authors utilize an outdated data matrix that largely ignores the extensive body of parareptile literature that has been produced in the last two decades. Secondly, the authors adhere to the interpretation of Piñeiro et al. (2012) that Mesosaurus possessed a lower lateral temporal fenestra, a condition that actually may be absent or ontogenetically variable within the taxon. Furthermore, temporal fenestration has been shown by several studies to be highly variable within Reptilia, raising concern about its utility as a phylogenetic character in analyses of Reptilia. Here we show how these two factors contribute to the results that were obtained by Laurin and Piñeiro (2017), and how future studies can alleviate these problems.

\section{MATERIALS AND METHODS}

A modified version of the data matrix from MacDougall et al. (2017), which was itself based in part upon the Laurin and Reisz (1995) matrix, was used for the phylogenetic analyses presented in this study. The matrix was modified by changing the codings for Mesosaurus so that they reproduce the codings used for Mesosauridae in Laurin and Piñeiro (2017). Furthermore, numerous synapsid and eureptilian taxa were added to increase the sample of non-parareptilian taxa. Several new characters were added to support the addition of these new taxa and to account for variation in temporal fenestration within them. The full character list and data matrix can be found in Data Sheets 1 and 2 respectively in Supplementary Material. The phylogenetic analysis was conducted in PAUP 4.0a159; a heuristic search (TBR) was performed with parsimony set as the optimality criterion, and all characters were equally weighted and unordered. Seymouria, Limnoscelis, and Orobates were designated as the outgroup taxa. Minimum branch lengths of less than zero were set to collapse.

The character codings that were changed for Mesosaurus are as follows: $7(1 \rightarrow 0), 8(-\rightarrow 0), 9(-\rightarrow 1), 10(-\rightarrow 1), 15(1 \rightarrow 0), 16$ $(? \rightarrow 0), 18(0 \rightarrow 1), 22(0 \rightarrow 1), 31(0 \rightarrow 1), 38(1 \rightarrow 0), 40(0 \rightarrow 1)$, $43(0 \rightarrow 1), 44(-\rightarrow 0), 45(-\rightarrow 1), 46(-\rightarrow 1), 52(1 \rightarrow 0), 61(0 \rightarrow 1)$, $65(1 \rightarrow 0), 66(? \rightarrow 0), 72(0 \rightarrow 1), 79(? \rightarrow 0), 84(1 \rightarrow 0), 93(? \rightarrow 1)$, $102(? \rightarrow 0), 103(0 \rightarrow 1), 106(? \rightarrow 1), 107(? \rightarrow 0), 108(-\rightarrow 0), 109(-$ $\rightarrow 1), 113(1 \rightarrow$ ?), $114(? \rightarrow 0), 116(1 \rightarrow 0), 117(1 \rightarrow 0), 121(? \rightarrow 0)$, $131(0 \rightarrow 1), 136(0 \rightarrow 1), 148(1 \rightarrow 0), 149(-\rightarrow 1), 150(0 \rightarrow 1), 154$ $(1 \rightarrow 0)$. All changes were based on the codings of Laurin and Piñeiro (2017).

The additional eureptile taxa are Paleothyris, Protorothyris, and Araeoscelis. The additional synapsid taxa are Eothyris, Cotylorhynchus, Oedalops, Eocasea, Edaphosaurus, Ianthasaurus, Archaeothyris, Archaeovenator, and Mycterosaurus. These new taxa were all scored at the generic level.

The new characters that were added to the analysis were as follows: (171) lower temporal fenestra narrow or tall, (172) postfrontal overall morphology, (173) dorsal ramus of jugal anteroposteriorly thick or narrow, (174) squamosal contact to lower temporal fenestra present or absent, (175) snout shape wider or taller, (176) maxilla lateral surface slopes dorsomedially or dorsolaterally, (177) anterior process of frontal length, and (178) posterior dorsal neural spine orientation. These characters were added to accommodate the numerous synapsid taxa that were also added to the analysis. Precise definitions for these new characters can be found in Data Sheet 1 in Supplementary Material.

A second phylogenetic analysis was carried out using this expanded matrix, but with the following nine characters related to temporal fenestration removed: (42) upper temporal fenestra present or absent, (43) lower lateral temporal opening present or absent, (44) if a lower temporal opening is present is it a fenestra or an emargination, (45) postorbital contribution to lower lateral temporal opening present or absent, (46) quadratojugal contribution to lower lateral temporal opening present or absent, (171) lower temporal fenestra narrow or tall, (172) postfrontal overall morphology, (173) dorsal ramus of jugal anteroposteriorly thick or narrow, and (174) squamosal contact to lower temporal fenestra present or absent.

\section{RESULTS}

The first phylogenetic analysis produced 9 optimal trees, each with a tree length of 669 . The strict consensus of these optimal trees (Figure 1A) shows Mesosaurus as the most basal parareptile taxon, with Parareptilia as the sister clade to Eureptilia. The second analysis, from which all temporal fenestration related characters were removed, produced 24 optimal trees, each with a tree length of 638 . The strict consensus of these optimal trees (Figure 1B) also finds Mesosaurus as the most basal parareptile taxon. Furthermore, the strict consensus trees from both analyses are slightly different with regard to the position of certain parareptile taxa. The clade Bolosauria is found closer to the base of Parareptilia in the second tree (Figure 1B), the position of Microleter mckinzieorum also varies between the two trees, and in the second tree Procolophonoidea, Nyctiphruretidae, Nycteroleteridae, and Pareiasauridae are found together in a polytomy. Interestingly, in both analyses the traditional taxonomic composition of Synapsida is not recovered, with the varanopid taxa being recovered as more closely related to the reptile lineage than to the other synapsids. This is a result that warrants further investigation in future studies.

\section{DISCUSSION}

\section{Updated Phylogenetic Analysis}

The data matrix used in the phylogenetic analysis of Laurin and Piñeiro (2017) was based upon the Laurin and Reisz (1995) matrix. They updated it with the addition of two parareptile taxa, the lanthanosuchoid Acleistorhinus pteroticus and the procolophonoid Owenetta kitchingorum, as well as the stemturtle Odontochelys semitestacea. Furthermore, several characters were recoded for the taxon Mesosauridae based on the authors' examination of fossil specimens, and many multistate characters that appeared to form morphoclines were ordered.

One of the main issues with this phylogenetic analysis is that Laurin and Piñeiro (2017) did not attempt to incorporate 


\section{A}

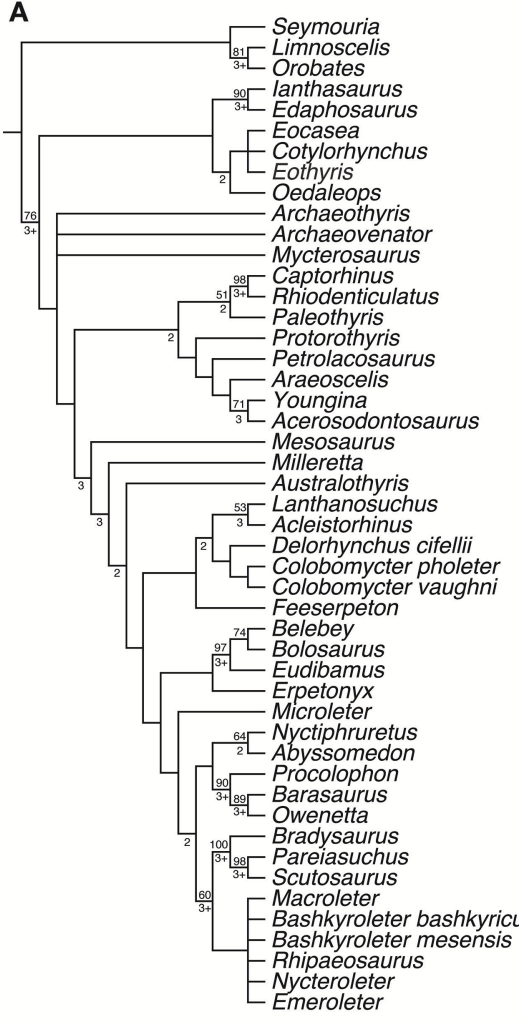

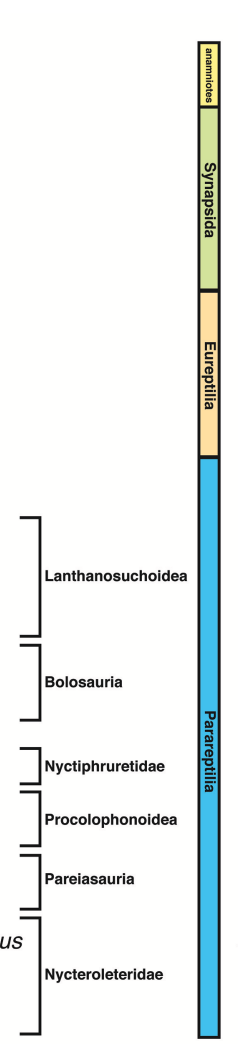

B

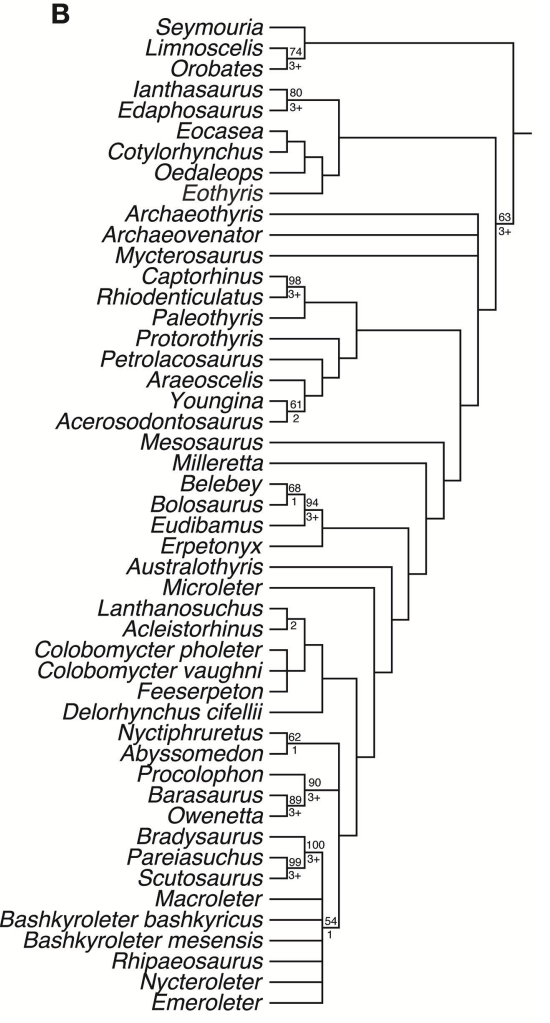

FIGURE 1 | Strict consensus trees found in the phylogenetic analyses. (A) Strict consensus of 9 optimal trees obtained from the analysis that included all characters, tree length $=669$, consistency index $(\mathrm{Cl})=0.302$, rescaled $\mathrm{Cl}=0.195$, retention index $=0.646$; (B) Strict consensus of 14 optimal trees obtained from the analysis that removed all temporal fenestration characters, tree length $=638, \mathrm{Cl}=0.303$, rescaled $\mathrm{Cl}=0.195$, retention index $=0.646$. Bootstrap support values (based on 1,000 replicates) are found above nodes, if no value is present it was $<50 \%$. Bremer support values are found below nodes, if no value is present the clade collapsed with the addition of one extra step.

additional information regarding the many newly described taxa or added character codings from any of the more recent phylogenetic analyses of Parareptilia, opting to instead use a data matrix more than 20 years old with some minor updates. The authors argued that this is because they are more familiar with the Laurin and Reisz (1995) matrix, and that this removes the issue of different systematists coding characters of an unfamiliar matrix differently. While we acknowledge that different researchers can code the same characters in different ways, this argument only holds up for matrices that include characters that are vague or not explained thoroughly. Recent analyses of various amniote clades have attempted to alleviate this issue by revamping characters and clearly indicating what is meant by each of the character states (Benson, 2012; MacDougall and Reisz, 2014; MacDougall et al., 2017), as facilitating repeatability is a key component of the scientific method. Likewise, if what the authors claim is true, how can anyone truly repeat and test their analyses if only the researchers that conceived it are able to code it properly? Thus, we feel that the (Laurin and Piñeiro, 2017) argument for not using a more recent data matrix has no merit.

Furthermore, since the Laurin and Reisz (1995) matrix was published there have been more than 20 new parareptiles described from across the clade, such as M. mckinzieorum
(Tsuji et al., 2010), Emeroleter levis (Tsuji et al., 2012), Delorhynchus cifelli (Reisz et al., 2014), Abyssomedon williamsi (MacDougall and Reisz, 2014), and the earliest parareptile Erpetonyx arsenaultorum (Modesto et al., 2015). The absence of any new parareptile taxa, aside from A. pteroticus and O. kitchingorum, is problematic, as the authors have ignored the vast majority of parareptile research that has occurred in the last two decades. The inclusion of more taxa into an analysis can often help to increase phylogenetic accuracy (Graybeal and Cannatella, 1998; Zwickl et al., 2002), which is extremely important when trying to determine where problematic taxa, such as Mesosaurus, will fall out within a phylogeny.

Finally, the inclusion of several supergeneric taxa in the Laurin and Piñeiro (2017) analysis is a further issue, as this has a tendency to introduce polymorphic character codings into the analysis (MacDougall and Reisz, 2014). There are numerous polymorphic codings within their new data matrix, which can weaken support values.

\section{Temporal Fenestration Within Mesosauridae}

For most of the Twentieth Century, temporal fenestration was used as a key characteristic to differentiate amongst the 
amniote groups Anapsida, Synapsida, and Diapsida (Osborn, 1903; Williston, 1917; Carroll, 1982). However, it is now apparent that this classification system is not as useful as it once was thought to be, with Anapsida no longer being considered a formal name (Modesto and Anderson, 2004), and many taxa with synapsid-type temporal fenestration being found outside of Synapsida (Tsuji et al., 2010; MacDougall and Reisz, 2014).

Temporal fenestration is quite prevalent within Parareptilia, with lower temporal fenestrae now known in numerous taxa (Cisneros et al., 2004; Tsuji et al., 2010; MacDougall and Reisz, 2014). With Mesosaurus potentially showing the presence of a lower temporal fenestra (von Huene, 1941; Piñeiro et al., 2012; Laurin and Piñeiro, 2017), it could represent yet another parareptile with temporal fenestration. With Mesosauridae being considered the sister to all other parareptiles by most studies, whether or not lateral temporal fenestration is present in Mesosauridae would be important for determining if lower temporal fenestrae are primitive for Parareptilia. However, other specimens of Mesosaurus do not appear to exhibit temporal fenestration (Modesto, 2006), and specimens with supposed temporal fenestration, such as that presented in Piñeiro et al. (2012), are extremely poorly preserved. Furthermore, Laurin and Piñeiro made no effort to reexamine the Mesosaurus specimens that had been previously described by Modesto (2006, 2010). This makes it difficult to say conclusively if lower temporal fenestration is present in Mesosaurus.

Regardless of whether or not a lower temporal fenestra is present in Mesosaurus, using lateral temporal fenestration as a phylogenetic character can be problematic due to its variability. Within Reptilia temporal fenestration is highly variable; this is the case for both Eureptilia and Parareptilia. With the numerous different shapes and sizes of lower temporal fenestrae and emarginations in parareptiles (Tsuji et al., 2010; MacDougall and Reisz, 2014) it is quite clear this region of their skull is highly variable. Likewise, Eureptilia exhibits similar amounts of variability with the diapsid condition, ranging from the typical diapsid upper and lower temporal fenestrae, to the loss of the lower temporal fenestra in Araeoscelis (Reisz et al., 1984), and even the loss of both the lower and upper temporal bars in snakes and amphisbaenians (Rieppel, 1993). This contrasts with Palaeozoic synapsids, which have a relatively stable lower temporal fenestra, lacking the variability observed in reptiles.

Furthermore, certain parareptile taxa such as Milleretta and Delorhynchus have been shown to have highly variable lower temporal fenestra (Gow, 1972; Haridy et al., 2016). In the case of Milleretta, a large lower temporal fenestra is present in juveniles, but this opening is completely lost in adult specimens (Gow, 1972). Delorhynchus also exhibits a large lower temporal fenestra as a juvenile and older specimens show that this opening is eventually split by a medial process of the jugal (Haridy et al., 2016), and it is unknown if this would eventually lead to the entire fenestra being lost in even older individuals. If temporal fenestration is present in some Mesosaurus specimens, this raises the question of if it is also ontogenetically variable, as in Milleretta and Delorhynchus. If this was the case it would cast further doubt on the utility of temporal fenestration as a phylogenetic character.
When all characters involving lateral temporal fenestration are removed from the phylogenetic analysis, the strict consensus tree that is produced (Figure 1B) resembles that recovered in recent studies of Parareptilia (Haridy et al., 2016; MacDougall et al., 2016, 2017; this study), although support values are lower for some clades (Figure 1). This suggests that whereas temporal fenestration can be useful in phylogenetic analyses of Parareptilia, it is not the only factor supporting the relationships we observe in the clade. Regardless of if it is present in Mesosaurus or not we still recover them as the sister taxon to all other parareptiles. Furthermore, when Mesosaurus is coded as polymorphic for lower temporal fenestration, it is still recovered in the same position as the other two analyses.

\section{Position of Synapsids in the Phylogenetic Analysis}

Both of our phylogenetic analyses recover Synapsida as not including varanopids, with the varanopids being found to be more closely related to the reptile lineage than to the other synapsids. This atypical result could potentially be due to several reasons: (1) the incomplete nature of many of the included synapsid taxa, (2) the fact that only a few extra characters were added to support these additions, or (3) varanopids are not synapsids. Large parareptile matrices such as ours rarely include this many synapsid taxa, and it is likely that more fine tuning to the taxa and characters will be required. This is beyond the scope of our current study, but warrants further investigation in the future.

\section{CONCLUSIONS}

Despite the interesting taxonomic implications of the new phylogenetic analysis of Laurin and Piñeiro (2017), their analysis has some apparent issues that may be affecting their results. The first issue is their use of an outdated data matrix with restricted taxon sampling excluding many of the numerous parareptile taxa that have been described over the last two decades. Whereas, the second issue is the variability associated with lateral temporal fenestration within Reptilia, especially ontogenetic variability, and whether or not temporal fenestration is present in mesosaurs. Using one of the most recent and up to date parareptile matrices, and the codings for Mesosauridae used by Laurin and Piñeiro (2017), we illustrate that the lack of taxa in their matrix combined with the variability of temporal fenestration in Reptilia are likely contributing to the tree topology that they obtained in their phylogenetic analysis, as our analyses recover mesosaurs as the sister taxon of all other parareptiles, regardless of whether or not temporal fenestration characters are used.

\section{AUTHOR CONTRIBUTIONS}

MM wrote the manuscript. SM, NB, AV, RR, and JF edited and proofread the manuscript. MM, SM, NB, RR, and JF prepared analyses. MM prepared figures and supplementary information. 


\section{ACKNOWLEDGMENTS}

MM is funded by a DAAD-Leibniz Postdoctoral Fellowship, SM is funded by a New Opportunities Fund award from the Canadian Foundation for Innovation and a grant from the Nova Scotia Research and Innovation Trust, RR is funded by an NSERC Discovery Grant, AV and JF are funded by a DFG grant from the German Research Foundation (DFG FR 2457/6-1). The

\section{REFERENCES}

Baur, G. (1889). Palaeohatteria Credner, and the Proganosauria. Am. J. Sci. 37, 310-313. doi: 10.2475/ajs.s3-37.220.310

Benson, R. B. J. (2012). Interrelationships of basal synapsids: cranial and postcranial morphological partitions suggest different topologies. J. Syst. Palaeontol. 10, 601-624. doi: 10.1080/14772019.2011.631042

Bever, G. S., Lyson, T. R., Field, D. J., and Bhullar, B. A. (2015). Evolutionary origin of the turtle skull. Nature 525, 239-242. doi: 10.1038/nature14900

Carroll, R. L. (1982). Early evolution of reptiles. Annu. Rev. Ecol. Syst. 13, 87-109. doi: 10.1146/annurev.es.13.110182.000511

Cisneros, J. C., Damiani, R., Schultz, C., da Rosa, A., Schwanke, C., Neto, L. W., et al. (2004). A procolophonoid reptile with temporal fenestration from the Middle Triassic of Brazil. Proc. R. Soc. Lond. B Biol. Sci. 271, 1541-1546. doi: $10.1098 /$ rspb.2004.2748

Cope, E. (1886). A contribution to the vertebrate paleontology of Brasil. Proc. Am. Philos. Soc. 25, 7-15.

Gauthier, J. A., Kluge, A. G., Rowe, T., and Benton, M. J. (1988). "The early evolution of Amniota," in The Phylogeny and Classification of the Tetrapods, Vol. 1, Amphibians, Reptiles, and Birds (Oxford: Clarendon Press), 103-155.

Gervais, P. (1865). Du Mesosaurus tenuidens, reptile fossile de l'Afrique australe. Rendus Acad. Sci. 60, 950-955.

Gow, C. E. (1972). The osteology and relationships of the Millerettidae (Reptilia: Cotylosauria). J. Zool. 167, 219-264. doi: 10.1111/j.1469-7998.1972.tb01731.x

Graybeal, A., and Cannatella, D. (1998). Is it better to add taxa or characters to a difficult phylogenetic problem? Syst. Biol. 47, 9-17. doi: $10.1080 / 106351598260996$

Haridy, Y., Macdougall, M. J., Scott, D., and Reisz, R. R. (2016). Ontogenetic change in the temporal region of the Early Permian parareptile Delorhynchus cifellii and the implications for closure of the temporal fenestra in amniotes. PLoS ONE 11:e0166819. doi: 10.1371/journal.pone.0166819

Laurin, M., and Piñeiro, G. H. (2017). A reassessment of the taxonomic position of Mesosaurs, and a surprising phylogeny of early Amniotes. Front. Earth Sci. 5:8. doi: 10.3389/feart.2017.00088

Laurin, M., and Reisz, R. R. (1995). A reevaluation of early amniote phylogeny. Zool. J. Linn. Soc. 113, 165-223. doi: 10.1111/j.1096-3642.1995.tb00932.x

MacDougall, M. J., Modesto, S. P., and Reisz, R. R. (2016). A new reptile from the Richards Spur locality, Oklahoma, U.S.A., and patterns of Early Permian parareptile diversification. J. Vertebr. Paleontol. 36:e1179641. doi: 10.1080/02724634.2016.1179641

MacDougall, M. J., and Reisz, R. R. (2014). The first record of a nyctiphruretid parareptile from the Early Permian of North America, with a discussion of parareptilian temporal fenestration. Zool. J. Linn. Soc. 172, 616-630. doi: $10.1111 /$ zoj.12180

MacDougall, M. J., Scott, D., Modesto, S. P., Williams, S. A., and Reisz, R. R. (2017). New material of the reptile Colobomycter pholeter (Parareptilia: Lanthanosuchoidea) and the diversity of reptiles during the Early Permian (Cisuralian). Zool. J. Linn. Soc. 180, 661-671. doi: 10.1093/zoolinnean/zlw012

Modesto, S. P. (2006). The cranial skeleton of the Early Permian aquatic reptile Mesosaurus tenuidens: implications for relationships and palaeobiology. Zool. J. Linn. Soc. 146, 345-368. doi: 10.1111/j.1096-3642.2006.00205.x publication of this article was funded by the Open Access Fund of the Leibniz Association and the Museum für Naturkunde Berlin.

\section{SUPPLEMENTARY MATERIAL}

The Supplementary Material for this article can be found online at: https://www.frontiersin.org/articles/10.3389/feart. 2018.00099/full\#supplementary-material

Modesto, S. P. (2010). The postcranial skeleton of the aquatic parareptile Mesosaurus tenuidens from the Gondwanan Permian. J. Vertebr. Paleontol. 30, 1378-1395. doi: 10.1080/02724634.2010.501443

Modesto, S. P., and Anderson, J. S. (2004). The phylogenetic definition of Reptilia. Syst. Biol. 53, 815-821. doi: 10.1080/10635150490503026

Modesto, S. P., Scott, D. M., MacDougall, M. J., Sues, H. D., Evans, D. C., and Reisz, R. R. (2015). The oldest parareptile and the early diversification of reptiles. Proc. R. Soc. Lond. B Biol. Sci. 282:20141912. doi: 10.1098/rspb.2014.1912

Osborn, H. F. (1903). On the primary division of the Reptilia into two sub-classes, Synapsida and Diapsida. Science 17, 275-276. doi: 10.1126/science.17.424.275-b

Piñeiro, G., Ferigolo, J., Ramos, A., and Laurin, M. (2012). Cranial morphology of the Early Permian mesosaurid Mesosaurus tenuidens and the evolution of the lower temporal fenestration reassessed. Comptes Rendus Palevol. 11, 379-391. doi: 10.1016/j.crpv.2012.02.001

Reisz, R. R., Berman, D. S., and Scott, D. (1984). The anatomy and relationships of the Lower Permian reptile Araeoscelis. J. Vertebr. Paleontol. 4, 57-67. doi: 10.1080/02724634.1984.10011986

Reisz, R. R., MacDougall, M. J., and Modesto, S. P. (2014). A new species of the parareptile genus Delorhynchus, based on articulated skeletal remains from Richards Spur, Lower Permian of Oklahoma. J. Vertebr. Paleontol. 34, 1033-1043. doi: 10.1080/02724634.2013.829844

Rieppel, O. (1993). "Patterns of diversity in the reptilian skull," in Patterns of Structural and Systematic Diversity The Skull, eds J. Hanken and B. K. Hall (Chicago, IL: University of Chicago Press), 344-390.

Tsuji, L. A., Müller, J., and Reisz, R. R. (2010). Microleter mckinzieorum gen. et sp. nov. from the Lower Permian of Oklahoma: the basalmost parareptile from Laurasia. J. Syst. Palaeontol. 8, 245-255. doi: 10.1080/14772010903461099

Tsuji, L. A., Müller, J., and Reisz, R. R. (2012). Anatomy of Emeroleter levis and the phylogeny of the nycteroleter parareptiles. J. Vertebr. Paleontol. 32, 45-67. doi: $10.1080 / 02724634.2012 .626004$

von Huene, F. (1941). Osteologie und systematische Stellung von Mesosaurus. Palaeontogr. Abt. A 92, 45-58.

Wegener, A. (1915). Die Entstehung der Kontinente and Ozeane. Braunschweig: Friedrich Viweg \& Sohn.

Williston, S. W. (1917). The phylogeny and classification of reptiles. Geology 25, 411-421. doi: 10.1086/622507

Zwickl, D. J., Hillis, D. M., and Crandall, K. (2002). Increased taxon sampling greatly reduces phylogenetic error. Syst. Biol. 51, 588-598. doi: $10.1080 / 10635150290102339$

Conflict of Interest Statement: The authors declare that the research was conducted in the absence of any commercial or financial relationships that could be construed as a potential conflict of interest.

Copyright (C) 2018 MacDougall, Modesto, Brocklehurst, Verrière, Reisz and Fröbisch. This is an open-access article distributed under the terms of the Creative Commons Attribution License (CC BY). The use, distribution or reproduction in other forums is permitted, provided the original author(s) and the copyright owner(s) are credited and that the original publication in this journal is cited, in accordance with accepted academic practice. No use, distribution or reproduction is permitted which does not comply with these terms. 